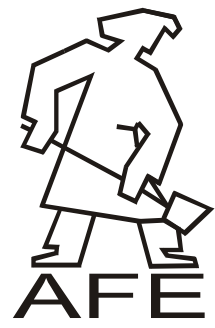

ARCHIVES

of

\title{
Logistics of Materials Flow in an Iron Foundry
}

\author{
S. Kukla \\ Department of Industrial Engineering, University of Bielsko-Biała, Willowa 2, 43-309 Bielsko-Biała, Poland \\ Corresponding author. E-mail address: skukla@ath.bielsko.pl
}

Received 24.05.2013; accepted in revised form 28.05.2013

\begin{abstract}
The article presents issues related to creating and realizing added value by logistic processes and processing in a casting enterprise. It discusses possibilities of improving systems of casts production by evaluating labour intensity of casts manufacture and analyzing manufacturing prime costs. Operations with added value, processes indirectly creating added value and operations without added value have been specified. The problem was presented on the example of materials flow design in a foundry, where casts are manufactured in expendable moulds and using automated foundry lines. On the basis of the Pareto analysis, a group of casts was specified whose manufacture significantly influences the functioning of the whole enterprise. Finishing treatment operations have been particularly underlined, as they are performed away from the line and are among the most labour-consuming processes during casts production.
\end{abstract}

Keywords: Application of information technology to the foundry industry, Transport systems in foundry, Logistics of material flow, Work ergonomics, Production systems rationalisation

\section{Introduction}

Efficient material flow in an enterprise consists mainly in supplying goods to particular participants of processes in a fluent and ordered way and with proper intensity, so that gathered reserves made it possible to satisfy needs in any place and time in an optimal amount. Reserves are kept not only because it is impossible to synchronize deliveries and distribution. Reserves may be indispensable because of the need to compile product range, to satisfy changeable customer requirements, as well as due to a possibility of disturbances during production processes realisation $[1,2]$.

Realizing logistic tasks requires a complex and systematic approach, which means allocating relatively wide competence to logistics. Products flow, keeping reserves, gathering and processing information are operations which demand using many technical means that can be included in logistic resources infrastructure. This infrastructure should assure fast and efficient flow of resources in an enterprise.

The notion of logistics includes, above all, managing transport and storage operations, which influence products flow from the places of origin to places of final consumption, taking into consideration the processes of information flow. Logistics in an enterprise is treated as an integrated system of shaping and controlling the processes of physical flow of goods and their information conditionings aiming at possibly best relations between the level of rendered services and the level and structure of prime costs [3].

Searching for more efficient methods of work, enterprises more and more frequently focus on limiting reserves and processes, and, above all, manufacturing prime costs. Such behaviour also found application of the casting industry by eliminating the operations and activities in manufacturing processes which do not add value to the produced casts $[4,5]$. 
Basing on the Toyota system philosophy (Toyota Production System) and on a widely understood Lean Manufacturing idea, casting production systems can be rationalised as well $[6,7]$.

Figure 1 presents basic aims of the four modules of a production system directed to continuous improvement.

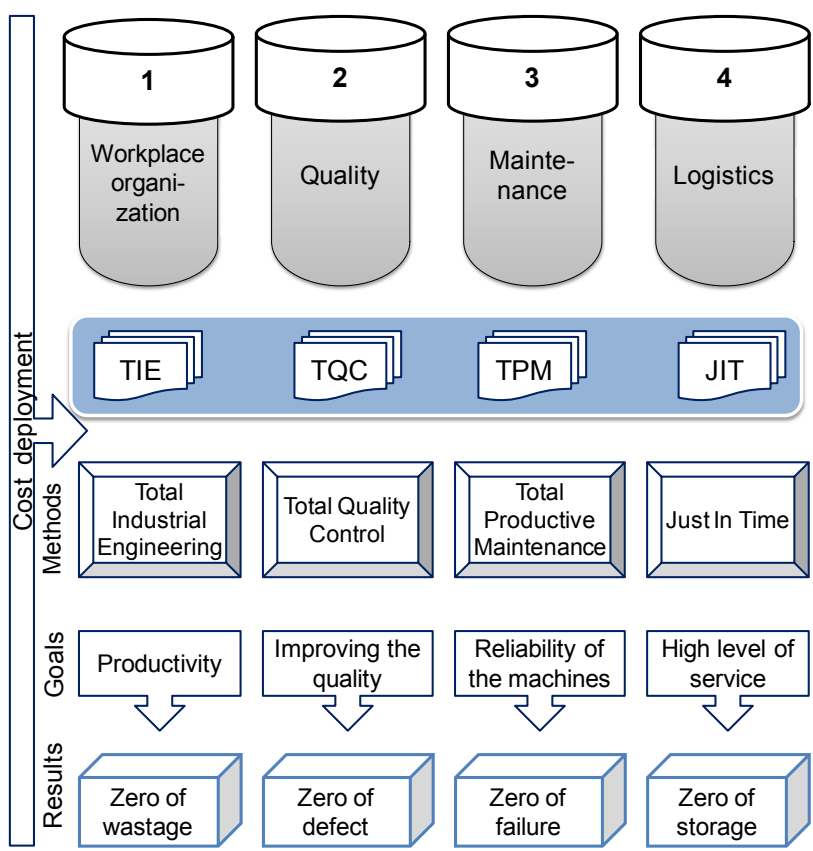

Fig. 1. Aims of production system improvement modules

The module of workstation is responsible for productivity, and its aim is zero losses. The quality system uses TQC tools in order to eliminate quality faults. The next module deals with managing technical devices exploitation to rationally use and achieve zero level of disturbances. The last module is responsible for the logistics of materials flow in an enterprise $[8,9,10]$.

\section{Research object, aim and methodology}

The presented research object is a system of manufacturing iron casts in expendable moulds on automated foundry lines (Fig. 2). Casts produced from nodular and grey cast iron are mainly dedicated to the automotive industry $[11,12]$.

After moulding sand and gate patterns have been separated, the gates are cleaned on through cleaners on foundry lines. After having been collected from the lines, casts also undergo control, additional cleaning, grinding and, optionally, initial machining.

The research aim is to reduce labour intensity of the produced iron casts. On the basis of the Pareto analysis, a group of casts produced in large numbers has been specified, for which financial advantages of taken actions should be significant.

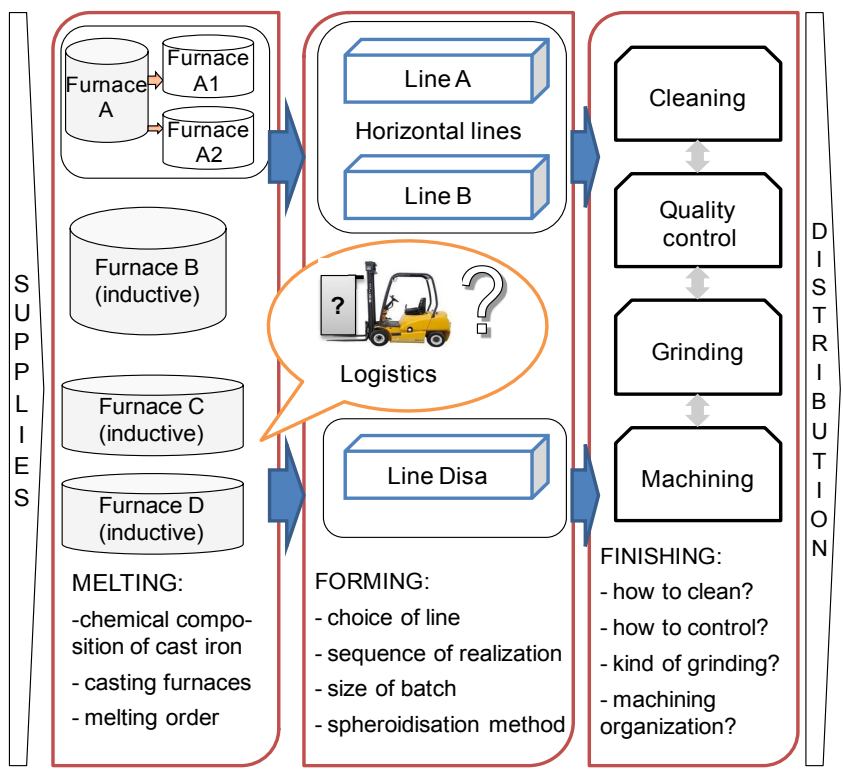

Fig. 2. Research object- manufacturing iron casts

The analysis of labour intensity was carried out with division into departments of melting, moulding and finishing units (Fig. 3). Research has shown that from the point of view of labour intensity, best rationalising effects can be achieved by improving finishing processes for the previously chosen group of castings.

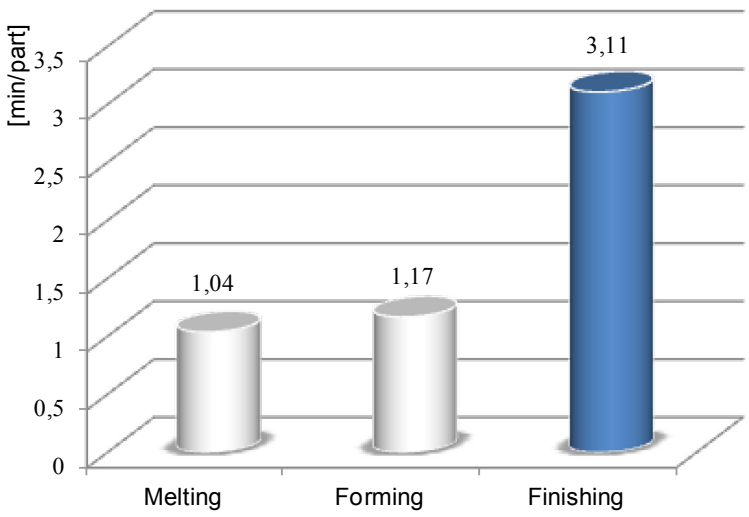

Fig. 3. Labour intensity for the chosen group of casts

Further research considered operations of grinding the remains after the gate assembly, grinding the surface of mould division, finishing of chills on the milling machine, scanning control, checking with a pattern and controlling using sound (the so called Ring Test).

After determining the model area and detailed analysis of logistic problems, a team was appointed to deal with organisation of workstations, whose aim was to create a model work centre, which can allow for best quality, maximum safety and possibly highest added value (Fig. 4).

Activities with added value, with partly added value as well as unnecessary ones, which do not add value to the produced 
casts, have been analysed. Also, the designed workstation has been controlled from the point of view of work ergonomics.

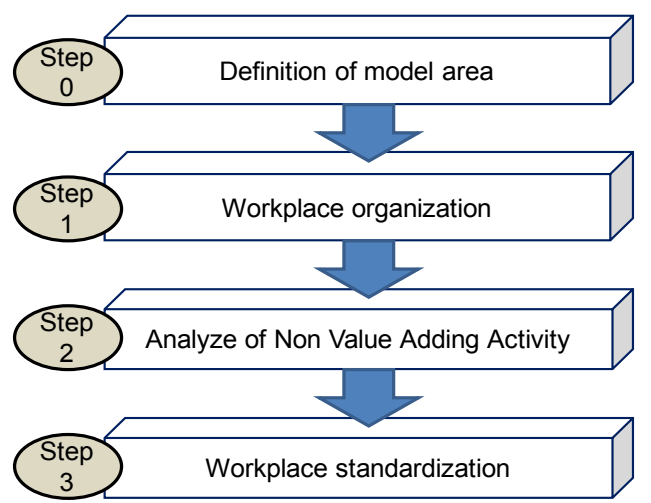

Fig. 4. Stages of workplace organisation

\section{Description of the obtained results}

Within the scope of improvement activities, operations without added value and difficult and unnatural ones have been specified and costs generated by them were determined.

First of all, it was suggested to relocate sound test operations performed in the main production hall next to grinding machining stations to a special sound-proof cabin. Thanks to these measures, it was possible to shorten the overall flow distance of the analysed crankshafts from 492 to 321 meters.

The next step involved analyzing technological requirements, on the basis of which is was concluded that improving division lines with cutters upon prior grinding is unnecessary.

Next, the operation's time has been regulated using the time study method. After labour intensity and technological requirements had been studied, reorganisation proposals for the work centre were put forward, with focus on the following objectives:

- $\quad$ Shortened time of exchanging empty containers into full ones thanks to trolleys on rails.

- Improved work ergonomics by using pneumatic devices to lean the containers towards a worker.

- Increased efficiency basing on reorganized grinding stations.

- Elimination of two workstations thanks to the application of a sound-proof cabin.

- Shortened waiting time for full containers with ready casts into empty ones by placing an additional empty container.

A scheme of a reorganized work centre was shown in Figure 5.

The proposed activities are also related to costs generated mainly by project realisation, creating and installing the soundproof cabin, as well as to costs of maintenance services and staff supervising the improvement project.

By comparing the costs of changes with savings which should be gained after project implementation, it has been estimated that the investment is going to pay back within about six months.

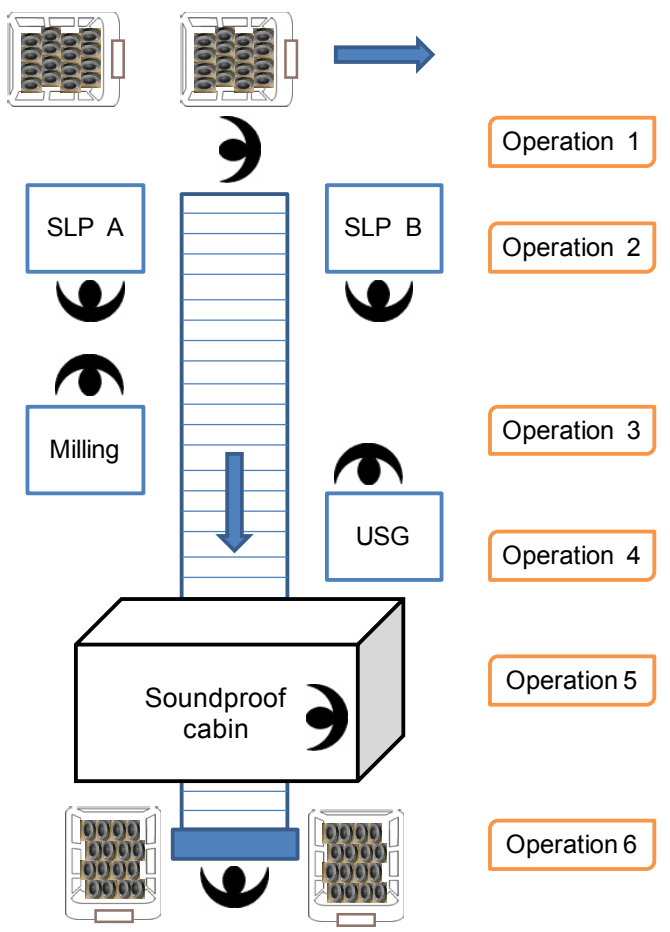

Fig. 5. Work Centre design

The stage of the new machining centre design considered such issues as minimum equipment with proper devices and tools for workstations, standardization of methods and the order of performing particular operations, and estimation of operations duration. The processes of eliminating all unnecessary materials at workstations, as well as preparing the rules for keeping cleanness and workstations operation were carried out according to the $5 \mathrm{~S}$ method.

The next step consisted in analysing tedious and unnatural activities in order to improve work ergonomics at a Workstation. Each activity has undergone analysis from the point of view of worker's muscles overloading, inconveniences caused by improper or unnatural posture, lack of mental comfort in case of operations which require significant attention and emotional nuisance by unpleasant activities. To compare the current state with the designed one, a point-based scale was used for evaluating particular ergonomic situations.

Thanks to joining and reorganising the work Centre, a number of economical solutions has been obtained. Transport routes have been shortened by nearly $35 \%$; it was possible to lower the level of activities without added value by over $45 \%$; work ergonomics at the machining work centre has been significantly improved as a result of eliminating inconvenient and unnatural operations and, above all, labour intensity of manufacturing one cast in the field of finishing has been decreased (Fig. 6). 


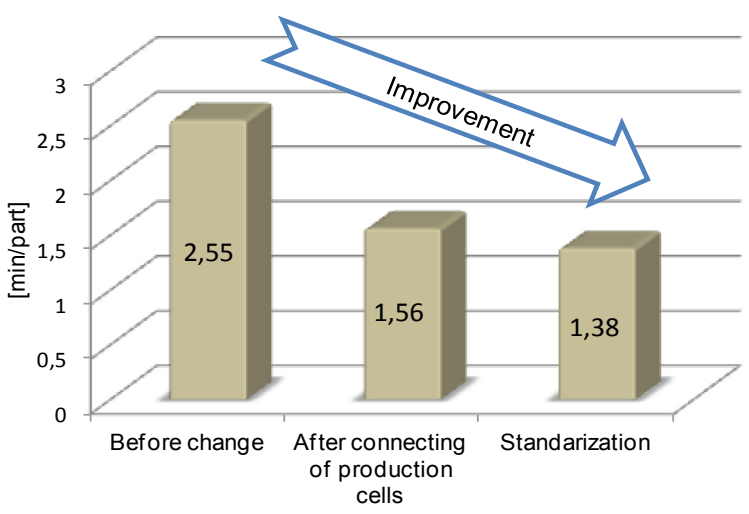

Fig. 6. Labour intensity of cast finishing operations

Such measures are surely going to contribute to lowering manufacturing prime costs, which in the yearly scale shall bring savings on the level of several hundred thousand PLN.

\section{Conclusions}

One of the basic tasks of contemporary logistics is to reduce the cost of flows and the size of reserves kept in an enterprise. These costs constitute a significant part of economic activity costs and their reduction by integrated logistic activities becomes an important source of rationalisation of production systems in foundries.

Logistics of materials flows is of considerable significance in eliminating losses in a foundry. Excessive manipulation of casts (transporting, arranging, packaging, storing) is a source of additional costs.

The concept presented in the paper aims at ensuring better organisation of workstations and achieving advantages by efforts directed towards obtaining the goals of zero losses, zero faults and zero reserves. Implementing this concept shows wastage in a foundry and eliminates it effectively. Connecting operations brings measurable financial advantages for a factory.

Taking into account work ergonomics is a significant factor in shaping production workstations. Analyzing difficult and unnatural operations allows to identify the activities which are troublesome for workers, and it may provide inspiration for implementing an improvement plan for a given workstation. Ergonomically designed workstations will make it possible for workers to reach retirement age in better health, and for employers to achieve higher profits. It can contribute to higher employee satisfaction, which influences the quality of the performed activities and tasks.
Rationalisation of foundry production systems key to lowering manufacturing prime costs related to iron casts production.

Thanks to precise determination of operations' labour intensity and costs calculation and allocation to specific activities it is possible to eliminate the operations which do not add value to products. Work standardisation at a workstation allows to develop procedures which help to order and repeat particular sequences of activities.

\section{References}

[1] Powell, D., Alfnes, E., Strandhagen, J. \& Dreyer H. (2013). The concurrent application of lean production and ERP: Towards an ERP-based lean implementation process. Computers in Industry 64, 324-335.

[2] Harris, R., Harris, C., Wilson, E. \& Womack J., (2010). Making materials flow: a lean material-handling guide for operations, production-control and engineering professionals. Cambridge: The Lean Enterprise Institute.

[3] Nyhuis, P. \& Wiendahl, H. P. (2009). Fundamentals of production logistic - theory, tools and applications. Berlin: Springer-Verlag.

[4] Yang, M., Hong, P. \& Modi, S. (2011) Impact of lean manufacturing and environmental management on business performance: An empirical study of manufacturing firms. Int. J. Production Economics. 129, 251-261.

[5] Womack, J. \& Jones, D. (2007) Lean solutions: how companies and customers can create value and wealth together. London: Simon \& Schuster.

[6] Dominici, G. \& Palumbo, F. (2012) Decoding the Japanese Lean Production System According to a Viable Systems Perspective. Springer Science Business Media, 153-171.

[7] Kerzner, H. (2010). Project management best practices: achieving global excellence, New York: Wiley.

[8] Narusawa, T. \& Shook, J. (2009). Kaizen Express fundamental for journey. Cambridge: The Lean Enterprise Institute.

[9] Matuszek, J. \& Kukla, S. (2009). Analysis of foundry production systems on the basis of modelling and simulation. Acta Mechanica Slovacia. 13(2), 106-111.

[10] Kukla, S. (2010). Production systems rationalisation on the example of iron foundry. Archives of Foundry Engineering. $10(2), 209-212$.

[11] Mysior, T. (2012). Production processes design on the bases of WCM system. Diploma dissertation. University of BielskoBiała, Poland.

[12] Kukla, S. (2012). Costs analysis of iron casts manufacturing. Archives of Foundry Engineering. 12(3), 45-48. 